\title{
Editorial
}

\section{INCLUSIÓN LABORAL EN LA REHABILITACIÓN INTEGRAL}

L

a Política Pública Nacional de Discapacidad formulada y aprobada por el Consejo Nacional de Política Económica y Social (CONPES), el 26 de julio de 2004, plantea dentro de las acciones de prevención de la discapacidad la identificación oportuna de riesgos que aumenten la condición de discapacidad.

Dentro de estos riesgos está el no desarrollar el potencial ocupacional de la persona con discapacidad; prevenir este riesgo va más allá de la ubicación/reubicación ocupacional. "La rehabilitación profesional, a este nivel, dirige su intervención a la ejecución de procesos encaminados al desarrollo o recuperación de la capacidad laboral de la persona, para el desempeño de su rol productivo, con base en los estándares de calidad establecidos por el sector laboral"1.

Se requiere para lograr el objetivo de preparar a la persona con discapacidad para la integración al medio laboral, desarrollar acciones de evaluación y orientación profesional, adaptación a una actividad productiva, apoyo a la formación profesional, ubicación/reubicación y seguimiento laboral.

La problemática de la vinculación laboral de personas con discapacidad fue abordada en el II Congreso Internacional de Rehabilitación Integral, reunido en Bogotá D.C. en el mes de julio de 2008. Las disciplinas de Fisiatría, Fisioterapia, Fonoaudiología, Terapia Ocupacional, Psicología, Pedagogía, Ergonomía, Derecho, Sociología, Mecatrónica, Arquitectura y Diseño Industrial, plantearon, desde diferentes enfoques, estrategias para implementar la política pública respecto a la inclusión laboral. También se dieron a conocer algunos programas que actualmente se ejecutan en este sentido.

Igualmente se presentaron investigaciones cuyos aportes al conocimiento están centrados en desarrollos tecnológicos, que se requieren para favorecer la integración/inclusión de las personas en condición de discapacidad.

A pesar de la formulación y aprobación de la política en el aspecto de inclusión laboral, de los programas y proyectos que se están realizado, aún no se ha visto el impacto sobre la vinculación laboral de las personas con discapacidad; las estadísticas del DANE, año 2007, indican que de la población discapacitada mayor de 10 años, solamente el 14\% está trabajando, y de este porcentaje el 25\% está vinculado al sector servicios.

Ministerio de Protección Social. Lineamientos de Política Habilitación/Rehabilitación Integral, pág. 34. 
Todavía tenemos un largo camino por recorrer para implementar la Política Pública de Discapacidad, especialmente en el aspecto de inclusión laboral. Sabatier y Mazmanian, citados por Roth Deubel ${ }^{2}$ plantean cinco condiciones bajo las cuales una decisión política, logre modificar de manera sustancial una situación y pueda alcanzar sus objetivos. Estas cinco condiciones son:

- El programa debe estar fundamentado en teoría sólida, relacionada con el cambio del comportamiento del público.

- La decisión política debe contener directrices no ambiguas y debe estructurar el proceso de implementación.

- Los dirigentes o responsables de los entes encargados de la implementación, deben disponer de capacidades políticas y de gestión importantes y sentirse comprometidos con los objetivos de la política.

- El programa debe disponer de apoyos activos durante todo el proceso de implementación por parte de grupos organizados y por algunos legisladores claves.

- La prioridad de los objetivos no debe estar disminuida por los cambios en las condiciones socioeconómicas, que debilitan los fundamentos técnicos de la teoría o del apoyo político que la respalda.

Implementar la Política Pública en relación con la inclusión laboral de las personas en situación de discapacidad, es un reto inmenso que nos compete a todos: legisladores, sector público, académicos, investigadores y empresarios.

BEATriz SuÁreZ de SARMiEnTo

Comité Editorial 